\title{
WHAT EXPLAINS THE RECENT JOBLESS RECOVERIES?
}

\author{
IRINA B. PANOVSKA \\ Lehigh University
}

This paper considers a correlated unobserved-components model for output, employment, and hours in order to disentangle the causes for the last three jobless recoveries. The composition of the structural shocks during recessions and the periods immediately following recessions has changed, as have the responses of employment and hours to those shocks. Recessions before 1984 were followed by recoveries driven by positive permanent shocks to output, whereas post-1984 recessions were followed by weak recoveries in demand. Employment is more sensitive to demand shocks post-1984, leading to weak recoveries in employment. In addition, hours and employment were complements before 1984, but are treated as substitutes after 1984. Much of the initial decrease in demand is now absorbed on the intensive margin.

Keywords: Jobless Recoveries, Labor Markets, Unobserved Components

\section{INTRODUCTION}

The past three recoveries in the United States have been markedly different from most postwar recoveries prior to 1990 , for which payroll employment returned to its prerecession level just a few months after the trough in output. The typical recovery from earlier recessions was characterized by fast job creation that quickly offset the job losses resulting from the recession. In contrast, employment growth was sluggish or negative for months and even years after the NBER-determined troughs in the past three recoveries. Figure 1 illustrates the difference in the behavior of payroll employment for each of the past three recoveries and for the average of the recoveries prior to 1984 in the three years following the trough. ${ }^{1}$

Following the past three recessions, the return to the peak level of employment was slow and sluggish, and employment continued to decline after the NBER trough, as shown by the downward-sloping paths of employment. Because of

I thank two anonymous referees, Luiggi Donayre, Yunjong Eo, Steven Fazzari, James Morley, Werner Ploberger, Raul Santaeulalia-Llopis, Tara Sinclair, and seminar participants at the University of Queensland, Monash University, the University of Auckland, Illinois State University, Bank of Canada, West Virginia University, Georgia State University, the University of Illinois Urbana-Champaign, Lehigh University, Miami University, and North Dakota State University. I would also like to thank the participants at the 2013 WEAI, the 2013 SBIES NBER NSF Seminar, the 2012 SNDE, the 2012 CEF, the 2012 MEG, and the Washington University Macroeconomics Working Group for helpful comments and discussions. I gratefully acknowledge the support of the Department of Economics and the Graduate School of Arts and Sciences at Washington University, and of the Olin Fellowship program. Address correspondence to: Irina B. Panovska, Department of Economics, Lehigh University, 621 Taylor Street, RBC 457, Bethlehem, PA 18015, USA; e-mail: irp213@lehigh.edu. 


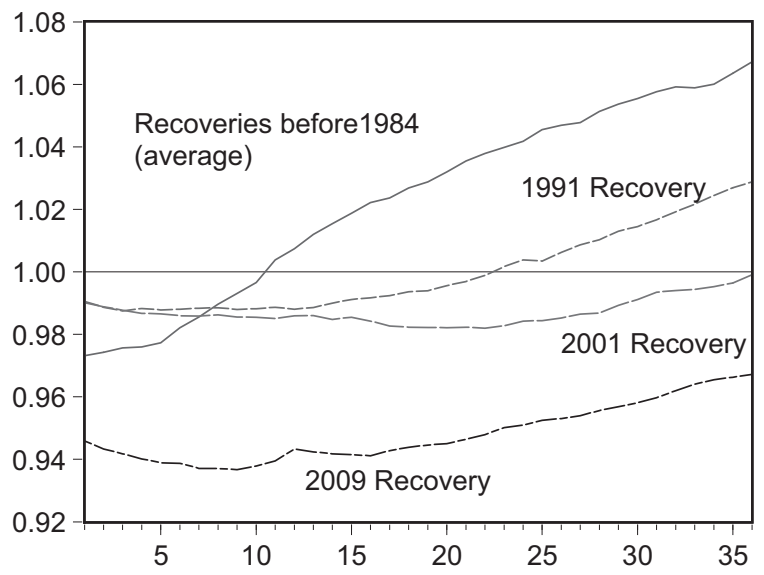

FIGURE 1. Behavior of payroll employment in the 36 months following the NBER trough (1 = level at the NBER peak).

this slow, delayed employment growth, many economists refer to the past three recoveries as "jobless." Although there is consensus in the literature regarding the stylized facts and the change in the dynamics of employment, there is no general consensus on the cause of jobless recoveries. Several explanations for this change in the relationship between labor market variables and output have been proposed in the theoretical literature. These include linking jobless recoveries to shifts across sectors and occupations, to employment overhang, to changes in the persistence and amplitude in the output cycle, and to changes in the nature of the labor market, where demand shocks are absorbed on the intensive margin or by using more flexible labor inputs.

The main goal of this paper is to empirically examine the extent to which changes in the relationship between output and labor market variables can explain the change in the behavior of employment during the past three recoveries. I construct an empirical model that nests the leading theoretical explanations for jobless recoveries. In particular, I examine whether the past three recoveries were driven by permanent movements and slower adjustments to permanent movements, whether there is significant evidence of overhang at the start of the past three recessions, or whether the structural relationship between output and the labor market variables changed after 1984. I use counterfactual analysis and I decompose the path of employment by type of structural shock in order to evaluate the contribution of structural change to the adjustment on different margins and the contribution of different structural shocks.

A large part of the change in the behavior of employment since the mid-1980s can be explained by changes in the responses of employment and hours to demand shocks. Although permanent movements play a more prominent role overall in the Great Recession and subsequent recovery, they are not relatively more important 
compared with the pre-1984 subsample, and the changes in the responses to cyclical demand shocks explain a substantial part of the differential in the path of employment.

The approach taken in this study is somewhat similar in spirit to the empirical approach of Engemann and Owyang (2010), who use a univariate model to explore whether the speed of adjustment of employment has changed over time and link changes in the speed of adjustment to the strands of the theoretical literature. However, the model here is different from Engemann and Owyang's because I directly incorporate the intensive margin and I identify transitory demand shocks based on restrictions from the theoretical models. My model is also related to the studies of Gomme (2005) and Faberman (2008), who examine the behavior of job creation and job destruction before and after 1984. In contrast with the approaches of Gomme and Faberman, who each examine only if there is evidence of a change in dynamics in the labor market at the start of the Great Moderation, I disentangle the channels implied by the different theoretical models.

The rest of this paper is organized as follows. Section 2 provides a brief overview of the theoretical explanations for the jobless recoveries. The empirical model and the link between the empirical model and the theoretical channels are presented in Section 3. The empirical results are presented in Section 4. In Section 5 I perform robustness checks, and Section 6 concludes.

\section{OVERVIEW OF THE LITERATURE}

The current theoretical literature that attempts to explain jobless recoveries can be broadly divided into four strands. The first strand postulates that the last three recessions and recoveries were driven by permanent shocks to the labor market, rather than transitory demand shocks, and that it takes a long time for employment to adjust to a permanent shock. Jaimovich and Siu (2012) link the slow recoveries to permanent shocks that cause shifts across occupational skill levels. Similarly, Andolfatto and McDonald (2005), and Garin et al. (2013) develop theoretical models that emphasize the role of reallocative shocks across sectors. In their empirical study, Groshen and Potter (2003) atrribute most of the slow growth in employment to permanent shifts across industries. Burger and Schwartz (2015) also find some empirical support for reallocation across sectors driving the slow recoveries in employment in OECD countries.

The second strand of the literature links the jobless recoveries to the concept of overhang. Koenders and Rogerson (2005) find that the recoveries after the 1970, 1990, and 2001 recession were driven by restructuring, because the long expansions caused firms to grow "fat." During long expansions, firms want to fill vacancies quickly and choose to hire employees who are not perfectly matched, thus causing employment to rise above its trend level and creating a significant overhang at the end of the expansion. A jobless recovery is simply a return to the long-run trend level. Berger (2012) also builds a theoretical model where jobless recoveries are explained by firms growing fat during long expansions. ${ }^{2}$ 
Bachmann (2012) proposes an alternative explanation that is linked to the duration of recessions and the persistence of business cycles. In his model, firms adjust on the intensive margin before adjusting on the extensive margin after short and shallow recessions. He attributes the slow employment growth following the short and shallow 1990 and 2001 recessions to this change in the persistence and amplitude of business cycles.

The fourth strand of the literature is linked to structural changes in the economy that occurred in the mid-1980s. Barnichon (2010) emphasizes the increasing importance of technology shocks relative to other shocks. In his model, sticky prices lead to slow adjustment of aggregate demand and to a temporary increase in unemployment and slow recoveries in labor markets in response to productivity shocks. Gali and van Rens (2010) link the changes in employment dynamics to declining labor market frictions. On the empirical side, Schreft and Singh (2003) and Hodgson et al. (2005) relate the changes in the labor market after the 1990s to the switch to just-in-time management of workers. If firms have access to flexible labor inputs like temporary employees, and are able to increase hours much more cheaply than they can increase employment, they can postpone hiring permanent employees until demand is sufficiently robust. ${ }^{3}$ In the following sections, I build an empirical model that I use to test the different theoretical explanations.

\section{EMPIRICAL MODEL}

\subsection{Econometric Model}

To examine if there are changes in the relationship between output and labor market variables before and after 1984, I consider an unobserved-components (UC) model where the innovations to the permanent component and the shocks that affect the cycle are allowed to be correlated, but the underlying structural shocks driving the model are orthogonal. A UC model of this type is particularly convenient for analyzing the behavior of employment, because it can be linked to the competing theories, and because it allows permanent shocks to affect the cyclical behavior of macroeconomic variables, allowing potential slow adjustment to permanent changes. ${ }^{4}$

The model used here is based on the following assumptions. First, I assume that the shocks to the output trend component are the only shocks that affect output in the long run. The output cycle responds to the output trend shocks and to transitory demand shocks. The employment trend component has two parts. Permanent movements in employment are driven by permanent movements in output and by long-run shocks that are not linked to changes in output (for brevity, I will refer to the second component of the permanent part of employment as "the labor trend" and to the shocks to this trend as "labor trend shocks"). These labor trend shocks encompass demographic, preference, and other exogenous shocks not linked to productivity. The employment cycle responds to output trend shocks and to labor trend shocks, allowing for slow adjustments in employment to 
permanent changes in output and the labor market. Furthermore, the employment cycle responds to demand shocks and to transitory shocks in employment. The hours per employee cycle respond to output trend shocks, to labor trend shocks, to demand shocks, and to transitory shocks in employment and hours per employee.

Formally, the empirical model is given by the equations

$$
\begin{gathered}
y_{t}=\tau_{y, t}+c_{y, t}, \\
e_{t}=\left(\gamma \tau_{y, t}+\tau_{e, t}\right)+c_{e, t}, \\
h_{t}=\mu_{h}+c_{h, t},
\end{gathered}
$$

where $y_{t}$ is a measure of real output, $e_{t}$ is a measure of employment, and $h_{t}$ is a measure of hours per employee. Output has an $I(1)$ stochastic trend:

$$
\tau_{y, t}=\mu_{y}+\tau_{y, t-1}+\eta_{y, t} .
$$

The stochastic trend in employment is the sum of two components:

$$
\operatorname{Trend}_{\mathrm{emp}, t}=\gamma \tau_{y, t}+\tau_{e, t}
$$

and

$$
\tau_{e, t}=\mu_{e}+\tau_{e, t-1}+\eta_{e, t} .
$$

The cyclical components are assumed to be stationary, and their dynamics can be described by the following equations:

$$
\begin{gathered}
\Phi_{1}(L)\left(y_{t}-\tau_{y, t}\right)=\lambda_{\tau_{y}, y} \eta_{y, t}+\epsilon_{y, t}, \\
\Phi_{2}(L)\left(e_{t}-\gamma \tau_{y, t}-\tau_{e, t}\right)=\lambda_{\tau_{y}, e} \eta_{y, t}+\lambda_{\tau_{e}, e} \eta_{e, t}+\lambda_{c_{y}, e} \epsilon_{y}+\epsilon_{e}, \\
\Phi_{3}(L)\left(h_{t}-\mu_{h}\right)=\lambda_{\tau_{y}, h} \eta_{y, t}+\lambda_{\tau_{e}, h} \eta_{e, t}+\lambda_{c_{y}, h} \epsilon_{y}+\lambda_{c_{e}, h} \epsilon_{e}+\epsilon_{h} .
\end{gathered}
$$

In this framework, firms can respond to output shocks by adjusting employment and by adjusting hours per employee. The stochastic component $\tau_{y, t}$ can be interpreted as the productivity trend that affects long-run output, and therefore affects long-run employment. The structural permanent shocks to output, $\eta_{y}$, can be interpreted as productivity shocks. The second trend component reflects permanent changes to the labor market that are not linked to output shocks. ${ }^{5}$ The coefficient $\gamma$ reflects how strongly permanent changes in output affect the employment trend, and will depend on the labor intensity of the production process. Permanent changes in the labor trend are allowed to affect the hours and employment cycle, to account for the fact that changes such as the hollowing out of the middle of the occupational distribution (job polarization) are precisely the kind of changes that 
would not affect overall productivity, but would affect the employment and the hours cycle. ${ }^{6}$

The shocks $\left[\eta_{y} \eta_{e} \epsilon_{y} \epsilon_{e} \epsilon_{h}\right]$ are the structural shocks that drive the model, and the impact coefficients $\lambda_{i j}$ describe the within-period response of the cyclical components $j$ to the shock $i$. The autoregressive coefficients describe the persistence of the cyclical components. The relative importance of permanent movements for the dynamics of employment is captured by the ratio of the volatilities of the permanent shocks, $\sigma_{\eta_{y}}$ and $\sigma_{\eta_{e}}$, relative to the overall variance of the cyclical components, and by the percentage of the movements in employment that are explained by each type of shock.

To identify the impact coefficients, I assume that demand shocks do not affect output in the long run. The shocks $\epsilon_{y}$ only affect the transitory component of output, and can be interpreted as demand shocks. This identification scheme is similar in spirit to Gali's (1999) long-run identification scheme. The transitory component of output is affected by the permanent shock to output, and the transitory demand shock. The transitory component of employment is affected by permanent output and labor shocks, by transitory demand shocks, and by transitory employment shocks. Within a period, hours per employee are affected by permanent output and labor shocks, by demand shocks, by transitory employment shocks, and by their own transitory shocks.

The coefficients $\lambda_{i j}$ play two important roles in this framework. They provide a direct way to capture the correlation between the cycles and the trends while keeping the structural shocks orthogonal, and they provide a measure of the responsiveness of the intensive and the extensive margin to different shocks. Defining the reduced-form shocks in terms of the structural shocks through the impact coefficients provides a way to orthogonalize the shocks that does not depend on restricting the responses of the cyclical components beyond the exogeneity restrictions implied by equations (7) through (9). The orthogonalization scheme used here nests the orthogonalization scheme used in the VAR models that study the response of hours to technology shocks [see, for example, Gali (1999)], but it is more general because it allows for the possibility that shocks other than productivity can have nonzero effects on employment in the long run, and it directly accounts for the possibility that some short-run fluctuations are caused by slow adjustments to permanent movements. ${ }^{7}$

The polynomials $\Phi(L)$ capture the autoregressive dynamics of the transitory components. The autoregressive polynomials $\Phi_{i}(L)=1-\phi_{i} L-. .-\phi_{i, p_{i}} L^{p_{i}}$ are assumed to have roots strictly outside the unit circle for $i=y, e, h$. To ensure identification in this model, $p_{i}$ has to be greater than 1 for each $i=1,2,3$. Following most of the UC literature, I set $p=2$ for all variables. ${ }^{8}$

There is a general consensus in the jobless recovery literature that the change in the behavior of employment was abrupt and occurred around the mid-1980s. Furthermore, there is a general consensus in the empirical macroeconomic literature that the Great Moderation (the sharp decline in the variance of most real macroeconomic variables) occurred around 1984. Because the timing of the start 
of the Great Moderation and the timing of the start of the jobless recoveries period is not the primary focus of this paper, I treat the break as exogenous and conduct a split-sample estimation. ${ }^{9}$ I estimate the model separately for the pre-Great Moderation period (1948q1-1983q4) and for the post-1984 period (1984Q1-2012q4), allowing all coefficients to change across subsamples. By allowing both the impact coefficients and the variances to change, I allow the correlation between the shocks to the cyclical components and the trend components to differ across subsamples. In this setup, changes in employment can occur through any of the channels implied by the theoretical models.

\subsection{Link between the Model and the Competing Theories}

In principle, one could build and solve a DSGE model that had adjustment costs along both margins, allowed for mismatches that accumulate and create the need for restructuring, and allowed for changes in the nature of both the permanent and the cyclical movements in output and in employment. Allowing for breaks in the DSGE parameters would therefore nest all four strands of the theoretical literature. Unfortunately, as discussed both in Ramey and Vine (2006) and in Bachman (2012), full structural analysis is quite challenging for models of this type, even for the simple model that has constant adjustment costs along only one margin. Instead, I use the reduced-form parameters described in the previous subsection to explore the implications of the theoretical models. To distinguish between the competing theories, I focus on four sets of key questions:

1. How much of the relative fluctuations in employment can be explained by permanent shocks, and how much can be explained by transitory shocks? Are post-1984 recoveries driven primarily by $\eta_{y}$ ? If the jobless recoveries are caused by permanent shocks, then there should be significant evidence of the increasing importance of permanent movements relative to cyclical movements, both across the business cycle, and in particular during recoveries. In this case, the ratio of the total trend volatility to the total cycle volatility of employment would increase, recessions would be primarily driven by the structural shocks $\eta_{y}$ and $\eta_{e}$, and the implied correlation between the total employment trend and cycle would increase, indicating slower adjustment to permanent shocks. In addition, the labor trend shock would explain a nontrivial portion of the movement in employment.

2. Is there significant evidence of overhang in the late stages of an expansion? If there is evidence that employment is significantly above its long-run trend level at the end of the expansions, this means that there is overhang, supporting the organizational restructuring theory. ${ }^{10}$

3. Are the lackluster recoveries induced purely by the shocks that affected the economy, not by structural changes between the variables? Declines in persistence of the output cycle would show up as statistically significant changes in the $\phi_{y, i}$ coefficients. If the jobless recoveries were driven by small shocks during the recession, but not by a structural change, then the structural parameters $\lambda_{i j}$ would remain unchanged. In this case, a counterfactual experiment that imposed the pre-1984 impact coefficients and used the actual shocks identified from the post-1984 period would lead to simulated 
counterfactual recoveries that looked like the observed slow recoveries. Similarly, if one performed a counterfactual experiment for the first subsample in which the observed structural shocks for the pre-1984 period were fed through through the system using the pre-1984 values for all parameters except the impact coefficients, the simulated paths of employment and hours should look like the observed paths of hours and employment before 1984.

4. Can the different responses of employment to output shocks be explained by the change in the sensitivity of employment and hours to overall economic activity? In the model, this would show up as a statistically significant increase in the impact coefficients $\lambda_{c_{y}, e}$ and $\lambda_{c_{y}, h}$, and as a change in the sign of the coefficient $\lambda_{c_{e}, h}$.

In short, a structural change in adjustment on different margins and structural changes in the labor market correspond to changes in the adjustment parameters. The structural reorganization hypothesis corresponds to employment rising significantly above trend during expansion. The sectoral shift hypothesis and the job polarization hypothesis correspond to increasing importance of permanent movements. Short and shallow recessions that were not accompanied by a structural change in the nature of the labor market would show up only as a decline in the persistence of the autoregressive polynomial and the volatility of the observed structural shocks, but not as a change in the impact coefficients.

\section{EMPIRICAL RESULTS}

The empirical results are organized into three parts. First, I examine whether there are significant changes in the parameters of the model. Although the overall volatilities for the total trend and the total employment cycle have declined, the ratio of trend to cycle volatility has not changed significantly. Similarly, the persistence of the cyclical components has not changed across subsamples. There is a significant change in the coefficient of impact of demand shocks on employment and hours, and a significant change in the coefficient of impact of employment on hours. As discussed in much more detail in Section 4.1, these parameter changes are consistent with a stronger adjustment on the intensive margin.

Second, conditional on the parameter estimates for each subsample, I decompose the observed path of employment to evaluate whether the last three recessions and the periods immediately following the recessions were driven by permanent or transitory shocks. The decompositions are discussed in Section 4.2. Although permanent shocks do play an important role, there is no evidence that the contribution of permanent shocks to the overall volatility of employment has increased significantly in the second subsample. In addition, the decompositions indicate that in the periods that followed the last three recessions, a lot of the sluggishness in employment can be attributed to weak demand.

Last, I perform counterfactual analysis to evaluate to what extent the changes in the impact coefficients affected the shape of the last three recessions and recoveries. I replace the estimated coefficients for the post-1984 period with the estimated impact coefficients from the pre-1984 sample, while keeping the 
structural shocks the same as the estimated structural shocks for the post-1984 sample. When the impact coefficients are replaced with the pre-1984 coefficients, the counterfactual paths of employment and hours during recessions and recoveries resemble the "old" recessions and recoveries. In particular, the counterfactual recessions are V-shaped, with a deeper recession followed by a faster bounceback. The counterfactual path for hours is much less volatile than the observed path for hours. The counterfactual experiments are discussed in detail in Section 4.3.

\subsection{Inference and Estimates}

The data series used are quarterly U.S. real GDP from BEA, total nonfarm payroll employment (converted to quarterly frequency using arithmetic averages), and Francis and Ramey's (2009) updated measure of aggregate hours (available from the authors' website) divided by the number of employees. The first subsample covers the period 1948q1-1983q4, and the second subsample covers the period 1984q1-2012q4. All series are converted to one hundred times the natural logarithm of the raw data series. ${ }^{11}$

The UC model has 24 parameters for each subsample, and it is identical to a reduced-form vector error correction model that has both a VAR and a vector MA component. Given that the model has a large number of parameters, estimation is conducted using Bayesian methods. I use a multiblock random walk chain with a Student $t$ proposal version of the Metropolis-Hastings (MH) algorithm. The main advantage of using Bayesian estimation over maximum likelihood estimation in this framework is the ability to handle the well-known pile-up problem directly. Previous research that uses UC models to decompose trend and cycle movements in macroeconomic variables frequently finds that the estimated parameters for many U.S. macroeconomic series are close to the boundary of the parameter space. ${ }^{12}$ Using Bayesian methods allows me to find an interior mode of the posterior, even with noninformative priors, thus circumventing the pile-up problem. The parameters were estimated by casting the model into state-space form and updating each parameter at each MH draw. The state-space representation for the UC model is given in Appendix A, and a detailed description of the sampler and the prior distributions are provided in Appendix B.

Table 1 presents the median estimates for the persistence of the cycles, measured by the sum of the autoregressive coefficients, the estimates for the key volatility and impact coefficients, and the posterior median for the change in the parameters. The implied total trend and cycle volatilities for employment are given in Table $2 .{ }^{13}$

The autoregressive coefficients $\phi_{i 1}, \phi_{i 2}$ (and thus the persistence of the cyclical components) are very similar across subsamples for all series. There is no evidence of a significant change in the persistence of any of the cycles. The estimated volatilities of both the permanent shocks and all three transitory shocks are lower for the second subsample, which is not surprising, because the break is chosen to coincide with the start of the Great Moderation. However, in this framework, the ratio of the overall trend volatility to the overall cyclical volatility is much 
TABLE 1. Posterior medians (standard deviations in parentheses)

\begin{tabular}{|c|c|c|c|}
\hline & 1948q1-1983q4 & $1984 q 1-2012 q 4$ & $\begin{array}{l}\text { Posterior distribution for } \\
\text { change in parameter }\end{array}$ \\
\hline$\phi_{y 1}+\phi_{y 2}$ & $0.48(0.08)$ & $0.53(0.09)$ & $0.05(0.06)$ \\
\hline$\phi_{e 1}+\phi_{e 2}$ & $0.69(0.07)$ & $0.76(0.13)$ & $0.07(0.15)$ \\
\hline$\phi_{h 1}+\phi_{h 2}$ & $0.77(0.06)$ & $0.81(0.11)$ & $0.04(0.10)$ \\
\hline$\gamma$ & $0.97(0.04)$ & $1.10(0.01)$ & $0.13(0.05)$ \\
\hline$\sigma_{\eta, y}$ & $1.43(0.10)$ & $0.99(0.09)$ & $-0.44(0.09)$ \\
\hline$\sigma_{\eta, e}$ & $1.41(0.15)$ & $0.95(0.04)$ & $-0.46(0.08)$ \\
\hline$\sigma_{\epsilon, y}$ & $0.75(0.19)$ & $0.52(0.09)$ & $-0.23(0.08)$ \\
\hline$\sigma_{\epsilon, e}$ & $0.30(0.02)$ & $0.19(0.04)$ & $-0.11(0.04)$ \\
\hline$\sigma_{\epsilon, h}$ & $0.77(0.02)$ & $0.64(0.02)$ & $-0.13(0.03)$ \\
\hline$\lambda_{\eta_{y}, y}$ & $-0.32(0.07)$ & $-0.49(0.02)$ & $-0.17(0.05)$ \\
\hline$\lambda_{\eta_{y}, e}$ & $-0.75(0.05)$ & $-0.92(0.03)$ & $-0.17(0.06)$ \\
\hline$\lambda_{\eta_{y}, h}$ & $0.10(0.07)$ & $0.08(0.07)$ & $-0.02(0.05)$ \\
\hline$\lambda_{\eta_{e}, e}$ & $-0.17(0.01)$ & $-0.19(0.01)$ & $-0.02(0.02)$ \\
\hline$\lambda_{\eta_{e}, h}$ & $0.01(0.002)$ & $0.02(0.01)$ & $0.01(0.01)$ \\
\hline$\lambda_{c_{y}, e}$ & $0.12(0.02)$ & $0.59(0.09)$ & $0.42(0.10)$ \\
\hline$\lambda_{c_{y}, h}$ & $0.10(0.03)$ & $0.31(0.01)$ & $0.21(0.04)$ \\
\hline$\lambda_{c_{e}, h}$ & $0.37(0.03)$ & $-0.20(0.05)$ & $-0.57(0.06)$ \\
\hline$\mu_{y}$ & $0.89(0.13)$ & $0.66(0.10)$ & $-0.22(0.07)$ \\
\hline$\mu_{e}$ & $-0.34(0.14)$ & $-0.44(0.12)$ & $-0.10(0.05)$ \\
\hline
\end{tabular}

TABLE 2. Implied total trend and cycle volatilities

\begin{tabular}{lccc}
\hline & Before 1984 & After 1984 & $\begin{array}{c}\text { Posterior distribution for } \\
\text { change in parameter }\end{array}$ \\
\hline$\sigma_{\text {TrendeMP }_{\text {EMP }}}$ & $1.98(0.16)$ & $1.45(0.07)$ & $-0.53(0.11)$ \\
$\sigma_{\text {Cycle }_{\text {EMP }}}$ & $1.53(0.07)$ & $0.99(0.10)$ & $-0.54(0.08)$ \\
$\rho_{\text {TrendEMP }_{\text {Cycle }}}$ & $-0.60(0.09)$ & $-0.81(0.10)$ & $-0.21(0.09)$ \\
$\sigma_{\text {Cycle }} / \sigma_{\text {Trend }}$ & $0.770(0.10)$ & $0.683(0.11)$ & $-0.09(0.05)$ \\
\hline
\end{tabular}

more informative than changes in the volatilities on their own. Both the sectoral shift hypothesis and the job polarization hypothesis imply that at the aggregate level, permanent movements became relatively more important compared with cyclical movements, both on the average, and during recessions and recoveries. In the UC framework, if permanent shocks became more important, this would mean that the variance of the overall employment trend would increase relative to the variance of the overall employment cycle, that the correlation between the trend and the cycle component would increase in absolute value (or both), or that more of the total movements in employment would be driven by $\eta_{y}$ and $\eta_{e}$. Although there is an overall decline in volatility, there is no evidence that the overall employment trend became more important relative to the employment 
cycle, nor that there is a significant decline in the relative volatility. The variance of the overall trend component in employment decreased from 1.98 to 1.45 , and the total variance of the cyclical component decreased from 1.53 to 0.99 , but the ratio of the overall trend to cycle volatility did not change significantly. Furthermore, the overall trend and the cycle are significantly negatively correlated in both subsamples. The correlations are -0.60 and -0.81 for the first and the second subsample, respectively. The large negative correlations indicate slow adjustment of employment to permanent shocks. Although the correlation does decrease across subsamples, there is no evidence that this change in the correlation, and thus the speed of adjustment, has changed significantly. ${ }^{14}$

The impact coefficients for the permanent output shock and the labor trend shock do not change drastically after the break. It is, however, important to note that the impact coefficients on employment are negative. The median estimated impact coefficient $\lambda_{\eta_{y}, e}$ is -0.75 for the first subsample and -0.92 for the second subsample, significantly different from zero. Permanent shocks to productivity have a transitory negative impact on the employment cycle, implying that employment does not adjust to steady state immediately following the shock. The negative impact coefficients are at odds with predictions based on RBC models, but they are consistent with Gali's (1999) New Keynesian DSGE model, where productivity shocks have a temporary negative effect on hours, and with Barnichon's (2010) findings for unemployment. Furthermore, the coefficients for the impact of the labor trend shocks on employment are negative and significant $(-0.17$ in the first subsample, -0.19 in the second subsample). Although the coefficients for the impact of the labor trend shock on hours per employee are not significantly different from zero, the median estimates are positive. These results indicate that a labor trend shock would cause the employment cycle to decrease temporarily, and that there is some evidence in favor of labor trend shocks causing slow adjustments in the cyclical component of employment. However, as discussed earlier, the results from Table 2 indicate that although the employment cycle does respond negatively to both output trend shocks and labor trend shocks, and although the employment cycle does adjust slowly to permanent shocks across both subsamples, there is no significant evidence that the employment cycle adjusts significantly more slowly post 1984.

The largest change occurred in the impact coefficients $\lambda_{c_{y}, e}, \lambda_{c_{y}, h}$, and $\lambda_{c_{e}, h}$, which capture the sensitivity of the employment and hours cycles to demand shocks and the link between employment shocks and the hours per employee cycle. The median estimate for the coefficient of impact of demand shocks $\left(\epsilon_{y}\right)$ on the employment cycle was 0.12 before 1984 and 0.59 after 1984 . In the first subsample, a positive demand shock equal to $1 \%$ of GDP increases log employment by $0.12 \%$. After 1984 , a positive demand shock increases employment by $0.59 \%$. Similarly, the hours per employee cycle respond more strongly to demand shocks post 1984 (an increase of $0.31 \%$ versus the $0.1 \%$ increase prior to 1984).

In addition to the large changes in the coefficients of impact of demand shocks on employment, there is a large change in the coefficient of impact of employment 
$1948 q 1-1983 q 4$

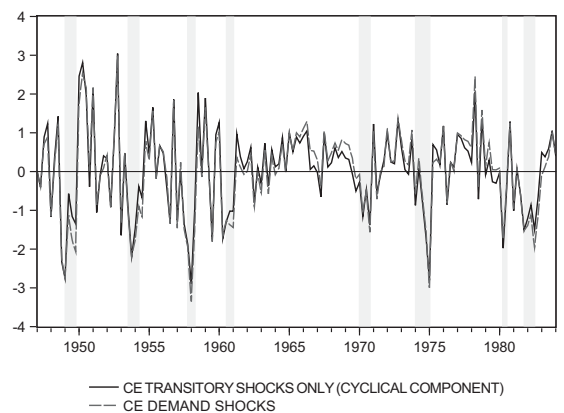

$1984 q 1-2012 q 4$

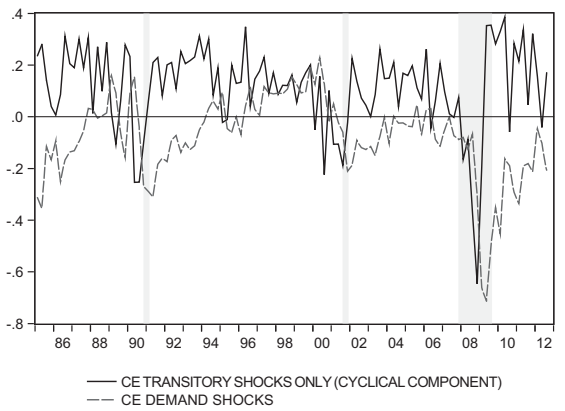

FIGURE 2. Decomposition of the path of employment. NBER recessions are shaded in gray.

on hours per employee. The impact coefficient changes from 0.37 to -0.20 , and the change is statistically significant. This switch from a positive to a negative impact coefficient is consistent with a switch toward just-in-time employment. After 1984, a negative shock to employment is associated with an increase in hours per employee, indicating that the different margins are now generally treated as substitutes, whereas employment and hours per employee moved in the same direction before 1984 .

\subsection{Trend-Cycle Decomposition and Evidence of Employment Overhang}

To further examine whether transitory shocks play a different role during recessions and recoveries after 1984, I decompose the path of employment by type of structural shock. This decomposition allows me to examine whether there is significant overhang and to evaluate the relative contribution of each type of structural shock. The setup is straightforward: given the structural shocks, I simulate the path of the employment cycle for the case where only one of the permanent shocks affects the system, for the case where only one of the transitory shocks affects the system, and for cases of interest when various combinations of the shocks affect the system. The approach used here is similar in spirit to the decompositions (frequently called historical decompositions) used by, inter alia, Gali and Rabanal (2004), Gali et al. (2012), and Santaeulalia-Llopis (2012). Figure 2 plots the posterior mode for the simulated series for the first subsample and for the second subsample. The figure plots the cyclical part of employment, defined as movements in employment that are driven by purely transitory components (demand shocks, $\epsilon_{y}$, and employment shocks, $\epsilon_{e}$ ), and the movements in the cyclical part of employment driven only by demand shocks, $\epsilon_{y}$. The left panel plots the path of employment before 1984, and the right panel plots the path of employment after 1984. Figure 3 plots the hours per employee series (which is equal to the hours per employee cycle, as discussed in Section 3), centered around zero, and the movements that are driven by transitory demand and employment shocks. 

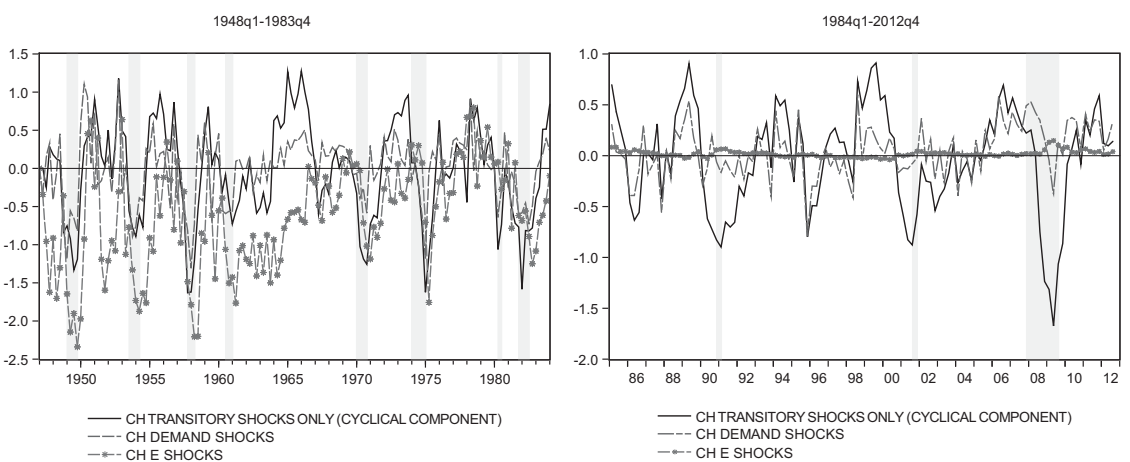

FIGURE 3. Decomposition of the path of mean-adjusted hours per employee by type of shock. NBER recessions are shaded in gray.

The full path decompositions for all types of shocks that include adjustments to permanent shocks are provided as supplemental graphs in the Online Appendix. It is important to note that in this paper I differentiate between the conventional UC cycle and the "cyclical part of employment." The cyclical part of employment presented here does not include adjustments to permanent shocks, whereas the conventional UC cycle does. The supplemental results in the Online Appendix include a comparison between Figure 2 and the results from a conventional UC model.

The cyclical part of employment declines during recessions and increases during expansions, tracing the NBER cycles relatively closely. Furthermore, whereas the cyclical part of employment is positive in the period immediately preceding the recessions, it starts to decline around the peak. Figure 2 illustrates that there is no evidence that the cyclical component of employment was increasing steadily during the first stages of the recession, or significantly higher at the end of long expansions than at the end of shorter expansions, indicating that the UC model does not support the overhang hypothesis. ${ }^{15}$ The left panel illustrates that most of the movements in the cyclical part of employment across the entire business cycle prior to 1984 were driven by demand shocks. After 1984, demand shocks are less important for explaining the movement in employment across the business cycle, but contribute to the slow recovery in employment. In particular, the right-handside panel of Figure 2 illustrates that the past three recessions were followed by a sluggish recovery in demand, which pushed the cyclical component of employment down.

Both Figure 2 and the more detailed decompositions that include all shocks (presented in the Online Appendix) illustrate that the nature of the shocks that drive recessions and recoveries has changed, and that the responses to those shocks have changed. In particular, recessions before 1984 were driven by declines in demand and followed by recoveries driven by positive permanent shocks to output. This result about the nature of the past three recessions is consistent 
TABLE 3. Variance decomposition (using posterior mode)

\begin{tabular}{|c|c|c|c|c|}
\hline & & $\begin{array}{l}\text { Log } \\
\text { employment }\end{array}$ & $\begin{array}{c}\text { Total } \\
\text { cycle } \\
\text { (UC) }\end{array}$ & $\begin{array}{c}\text { Purely } \\
\text { cyclical } \\
\text { component }\end{array}$ \\
\hline \multicolumn{5}{|c|}{$1948 q 1-1983 q 4$} \\
\hline \multirow{2}{*}{$\begin{array}{l}\text { Trend-cycle } \\
\text { decomposition }\end{array}$} & Total trend & $91 \%$ & - & - \\
\hline & $\begin{array}{c}\eta_{y} \\
\text { (Trend+cyclical adjustments) }\end{array}$ & $96 \%$ & $81.0 \%$ & - \\
\hline \multirow{3}{*}{ By type of shock } & $\begin{array}{c}\eta_{e} \\
\text { (Trend+cyclical adjustments) }\end{array}$ & $2.2 \%$ & $1 \%$ & - \\
\hline & $\varepsilon_{y}$ & $1.5 \%$ & $15.4 \%$ & $86.7 \%$ \\
\hline & $\epsilon_{e}$ & $0.3 \%$ & $2.6 \%$ & $14.4 \%$ \\
\hline \multicolumn{5}{|c|}{$1948 q 1-1983 q 4$} \\
\hline \multirow{2}{*}{$\begin{array}{l}\text { Trend-cycle } \\
\text { decomposition }\end{array}$} & Total trend & $90 \%$ & - & - \\
\hline & $\begin{array}{c}\eta_{y} \\
\text { (Trend+cyclical adjustments) }\end{array}$ & $97 \%$ & $85 \%$ & - \\
\hline \multirow[t]{3}{*}{ By type of shock } & $\begin{array}{c}\eta_{e} \\
\text { (Trend+cyclical adjustments) }\end{array}$ & $1.1 \%$ & - & - \\
\hline & $\varepsilon_{y}$ & $1.1 \%$ & $8.68 \%$ & $57.8 \%$ \\
\hline & $\epsilon_{e}$ & $0.8 \%$ & $6.3 \%$ & $42.1 \%$ \\
\hline
\end{tabular}

with Sinclair's (2010) findings. The labor trend shocks decrease employment by a cumulative $0.2 \%$ and $0.3 \%$ following the 1990 and 2001 recoveries, but these decreases are not statistically significant. ${ }^{16}$ The net decrease due to $\eta_{e, t}$ following the Great Recession is $0.5 \%$. The findings for the Great Recession are qualitatively and quantitatively consistent with the results from Stock and Watson (2012).

The movements in employment caused by purely transitory shocks match the NBER recessions and the periods following the recession quite well. As illustrated in Figures 2 and 3, purely transitory shocks still explain a non-negligible part of the movements in both series, especially during recessions and the periods immediately following recessions. Performing variance decomposition for the entire subsample 1984-2012q4 leads to similar conclusions. The key results are presented in the last columns of Table 3, which parallel the usual variance decomposition of the employment cycle from studies that focus solely on the cyclical component. Even though permanent shocks play a big role for the overall dynamics of employment, demand shocks explain, on the average, $2 \%$ of the fluctuations in the level of employment, which is comparable to the level of business cycle fluctuations. The decompositions in Figure 2 and the variance decomposition indicate that the last three recessions were caused by a combination of negative permanent shocks with 
negative demand shocks in the subsequent periods and in the periods immediately following the recessions.

\subsection{The Role of the Impact Coefficients and Estimated Job Losses}

In the previous two subsections, I examined whether the persistence of the cycles has changed, whether there is any evidence in favor of overhang, and whether permanent movements are more important relative to transitory movements. In this subsection, I tackle the last channel: I analyze whether change in the adjustment at different margins leads to significant job losses. This will allow me to evaluate whether the slow recoveries were driven solely by the nature of the structural shocks that hit the economy, or by changes in the structural coefficients. In disentangling the role of the different channels implied by the theoretical models, one of the key issues is to what extent the change in the impact coefficients (i.e., in the sensitivity of employment and hours to real macroeconomic shocks) affected the path of employment and hours. Although there is no evidence that the persistence of the cyclical components has changed, there is overwhelming evidence that the amplitude and the volatility of the structural shocks declined post-1984, as shown in Tables 1 and 2. The theoretical models that link jobless recoveries to the persistence and the amplitude of the business cycle are based on the assumption that short and shallow recessions are absorbed on the intensive margin, but they also predict that a short and shallow recession would have been absorbed on the intensive margin before 1984, and that a large recession after 1984 would be absorbed on the extensive margin. Because the theoretical models are not mutually exclusive, it is possible that the change in the impact coefficients and short and shallow recessions amplified the slow recovery in employment. For example, it is possible that a recession could be short and shallow and absorbed on the intensive margin, and that the impact coefficients changed because firms now have access to more flexible labor inputs and absorb all recession on the intensive margin first. It is also possible that although the changes in the impact coefficients are statistically significant, they may not be economically significant, and that all of the differences in the path decompositions between subsamples are driven by the different sequences of shocks that hit the economy; these shocks may not be less persistent, but may lead to short and shallow recessions. ${ }^{17}$ To shed light on these questions, I perform a set of counterfactual experiments for each subsample. I keep the estimated structural shocks from each subsample, but change the impact coefficients to evaluate how the observed shocks would have been transmitted had the impact coefficients been different. To isolate the effects of each impact coefficient, I perform a counterfactual analysis where I change only one of the impact coefficients to its pre-Great Moderation value, and leave all other parameters at their post- 1984 values. ${ }^{18}$ I perform the same counterfactual experiment for the pre-1984 period, changing only a subset of parameters to the post-1984 values. The approach used here is similar in spirit to the approach used 

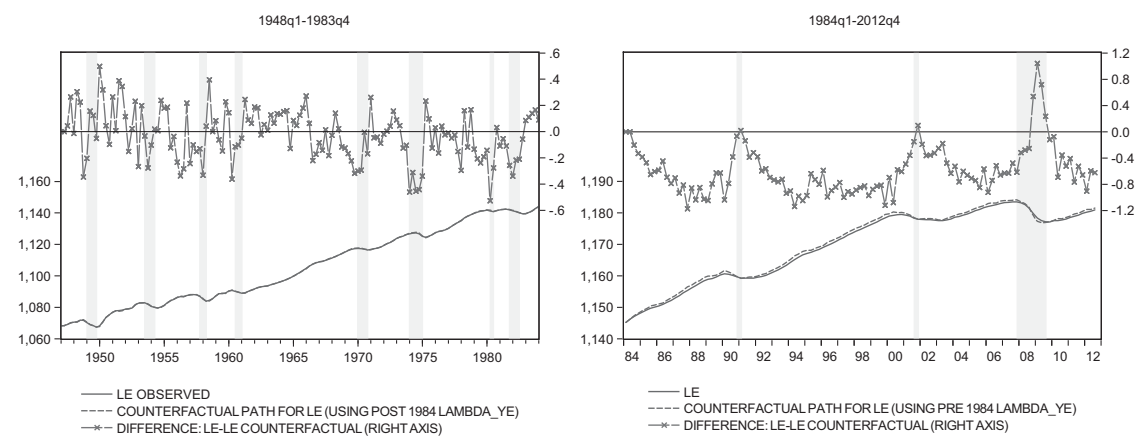

FIGURE 4. Observed employment, counterfactual path, and the difference between the observed path and the counterfactual path.

by Kim et al. (2008), who use counterfactual analysis to analyze the sources of the Great Moderation, and to the approach used by Morley and Singh (2016), who use counterfactual analysis to study the role of inventory mistakes in reducing the volatility of output relative to the volatility of sales. The counterfactual analysis is performed as follows:

1. The parameter values and the reduced form shocks for both subsamples were obtained first.

2. For a given parameter draw from the MH sampler for a subsample of interest, the impact coefficient of interest was replaced with the mode for the other subsample.

3. The orthogonalized shocks were fed through the system, using the alternative values for the impact coefficients.

The shocks that were fed through the model for the counterfactual analysis in the second subsample for the 1990 and 2001 recessions are consistent with short and shallow recessions and somewhat slower recoveries in output. If the counterfactual path of employment for the second subsample has V-shaped recessions and recoveries in employment for 1990 and 2001 (similar to the pre-1984 shape), and bigger increases in employment following the recessions, then this can be interpreted as evidence in favor of the hypothesis that the change in the impact coefficients contributed to the joblessness by itself. Similarly, the structural shocks for the pre1984 period are consistent with deeper recessions and faster recoveries in output. If the counterfactual paths for employment for the pre-1984 sample exhibit less firing during a recession, or less hiring during a recovery, this is further evidence that the adjustment on different margins is not driven solely by a change in the nature of the shocks themselves.

Figure 4 plots the observed path of employment, the counterfactual path for employment when the impact coefficient $\lambda_{c_{y}, e}$ is set to the new (old) value, and the difference between the observed path of employment and the counterfactual path. The left panel plots the counterfactual analysis for the first subsample (where the impact coefficient is set to the post-1984 value), and the right panel plots the 
counterfactual path post 1984 . When the impact coefficient is set to the post-1984 values, the decline in employment during recessions is slightly faster, driven by the fact that the recessions before 1984 were caused by demand shocks, and that employment is more sensitive to demand shocks post 1984. The counterfactual path for employment is slightly above the observed path during the initial stages of the 1990 and 2001 recessions, indicating that there would have been slightly more firing and the recessions would have been more V-shaped, but the difference for the recession part is quite small. The V-shape for the 2007 recession, however, is quite pronounced. There would have been a faster decline and a much faster recovery in employment had the impact coefficients not changed. For all three recoveries, the observed path of employment is below the counterfactual path immediately following the recession, indicating that employment would have increased faster had the impact coefficients not changed. Similarly, employment would have recovered slower before 1984 (the counterfactual path is below the observed path for almost all recovery episodes). The counterfactual series for hours per employee are much more volatile in the second subsample. This is the case even for the shocks that were consistent with relatively deep recessions and robust recoveries in the 1950s and 1980s. The observed standard deviation for $c_{h}$ is 0.54 for the first subsample, whereas the standard deviations for the counterfactual series generated using $\lambda_{c_{y}, h}$ and $\lambda_{c_{e}, h}$ are 1.14 and 1.76 , respectively. When the impact parameters are held at their prebreak levels, the hours per employee cycle are much less volatile than the observed series. In particular, the observed standard deviation for $c_{h}$ is 0.49 , and the standard deviations for the counterfactual series are 0.11 and 0.18 .

The counterfactual simulations for the post 1984 sample show that when the old impact coefficients are used, employment recovers faster, and hours per employee are much less volatile than the observed series after 1984 (see Figure 5). If the impact coefficients on employment had not changed, employment would have exhibited patterns similar to those observed prior to 1984-a slightly more rapid decline at the start of the recession caused by a negative shock, and a faster bounce back. This is particularly noticeable during the Great Recession: there would have been a more pronounced decline at the start of the recession and a bigger increase at the end of the recession. Again, these results are in line with the theories that indicate that both the nature of the shocks that drive the business cycles, and the structural link between output and the labor market, have changed. ${ }^{19}$

\section{THE EFFECTS OF THE GREAT RECESSION AND THE VOLATILE PERIOD IN THE 1950S}

Because the Great Recession was much larger than the 1990 and 2001 recessions, there has been an ongoing debate in the last few years whether the start of the Great Recession was the end of the Great Moderation, and whether it was structurally different from the 1990 and 2001 recessions. If the Great Recession was indeed the start of a new period in U.S. economic history, then the results of the previous 
$1948 q 1-1983 q 4$
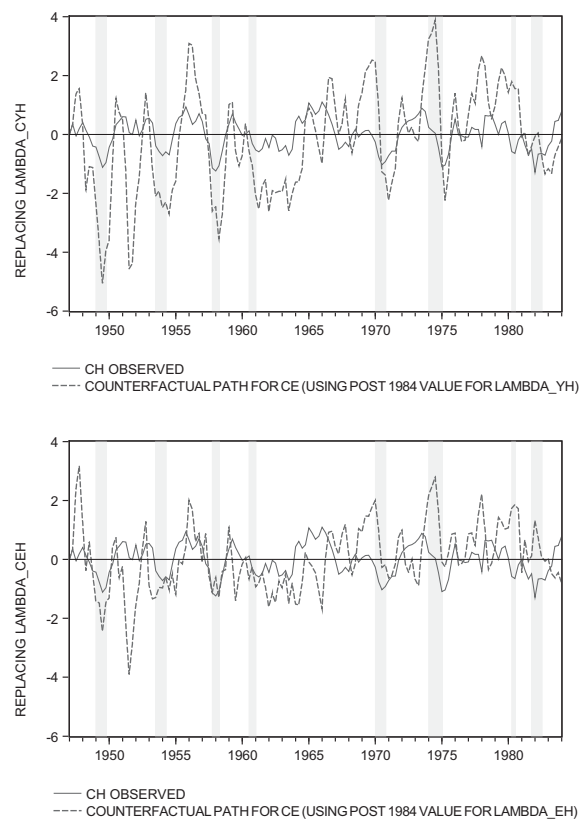

$1984 q 1-2012 q 4$

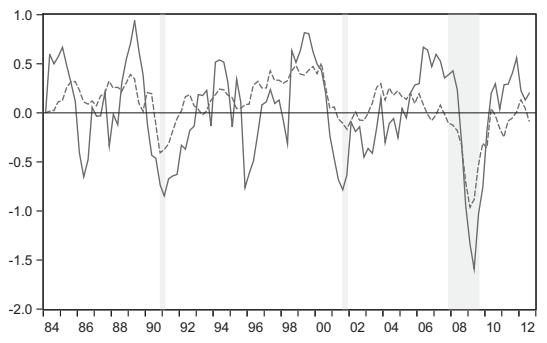

- CH OBSERVED

COUNTERFACTUAL PATHFORCE (USING PRE 1984 VALUE FOR LAMBDA_YH)

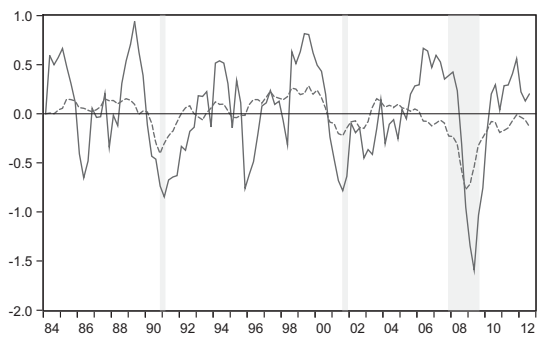

---- COUNTERFACTUAL PATH FORCE (USING PRE 1984 VALUEFORLAMBDA_EH)

FIGURE 5. Observed vs. counterfactual paths for hours per employee. The top row is counterfactual paths when the coefficient $\lambda_{c_{y}, h}$ is changed; the bottom panel is counterfactual paths when the coefficient $\lambda_{c_{e}, h}$ is changed.

sections might be biased because the Great Recession was so large. Similarly, the first subsample used here includes the volatile 1950s, and there are eight recessions in the first subsample, compared to the three recessions in the second. To ensure that the results are not distorted by the presence of large outliers, I reestimate the model given by equations (1)-(9) for a shorter first subsample that starts in 1960q1 and ends in 1983q4, and for a shorter second subsample that ends in 2006q4. The estimates for the shorter and the baseline subsamples are presented in Table 4.

The first and third columns of the table reproduce the estimates from Table 2; the second and fourth columns present the estimates for the shorter subsamples. Not surprisingly, the standard deviations of almost all the estimates are slightly larger when the Great Recession is included, but none of the parameter estimates for the impact parameters change significantly, implying that including the Great Recession data does not distort the results. The Great Recession was larger and deeper than the previous two recessions, but the recovery and the responses of employment mimic those observed during the previous two recoveries, conditional on the shocks that were observed. In particular, as shown in the supplemental graphs in the Online Appendix, and as discussed in Section 4.2, much of the initial decline during the Great Recession was caused by a large negative $\eta$, leading to a larger proportion of the volatility in employment being explained by permanent 
TABLE 4. Robustness analysis: parameter estimates for shorter subsamples

\begin{tabular}{lcrrr}
\hline & $1948 \mathrm{q} 1-1983 \mathrm{q} 4$ & $1960 \mathrm{q} 1-1983 \mathrm{q} 4$ & $1984 \mathrm{q} 1-2012 \mathrm{q} 4$ & $1984 \mathrm{q} 1-2006 \mathrm{q} 4$ \\
\hline$\phi_{y 1}+\phi_{y 2}$ & $0.48(0.08)$ & $0.50(0.02)$ & $0.53(0.09)$ & $0.56(0.14)$ \\
$\phi_{e 1}+\phi_{e 2}$ & $0.69(0.07)$ & $0.74(0.09)$ & $0.76(0.13)$ & $0.80(0.07)$ \\
$\phi_{h 1}+\phi_{h 2}$ & $0.77(0.06)$ & $0.78(0.12)$ & $0.81(0.11)$ & $0.79(0.10)$ \\
$\gamma$ & $0.97(0.04)$ & $1.16(0.05)$ & $1.10(0.01)$ & $1.2(0.11)$ \\
$\sigma_{\eta, y}$ & $1.43(0.10)$ & $1.32(0.13)$ & $0.99(0.09)$ & $0.77(0.06)$ \\
$\sigma_{\eta, e}$ & $1.41(0.15)$ & $1.75(0.27)$ & $0.95(0.04)$ & $1.14(0.06)$ \\
$\sigma_{\epsilon, y}$ & $0.75(0.19)$ & $0.61(0.14)$ & $0.52(0.09)$ & $0.41(0.05)$ \\
$\sigma_{\epsilon, e}$ & $0.30(0.02)$ & $0.45(0.17)$ & $0.19(0.04)$ & $0.21(0.08)$ \\
$\sigma_{\epsilon, h}$ & $0.77(0.02)$ & $0.82(0.05)$ & $0.64(0.02)$ & $0.49(0.02)$ \\
$\lambda_{\eta_{y}, y}$ & $-0.32(0.07)$ & $-0.38(0.04)$ & $-0.49(0.02)$ & $-0.45(0.04)$ \\
$\lambda_{\eta_{y}, e}$ & $-0.75(0.05)$ & $-0.89(0.08)$ & $-0.92(0.03)$ & $-1.01(0.07)$ \\
$\lambda_{\eta_{y}, h}$ & $0.10(0.07)$ & $0.15(0.07)$ & $0.08(0.07)$ & $0.14(0.09)$ \\
$\lambda_{\eta_{e}, e}$ & $-0.17(0.01)$ & $-0.08(0.02)$ & $-0.19(0.01)$ & $-0.28(0.03)$ \\
$\lambda_{\eta_{e}, h}$ & $0.01(0.002)$ & $0.07(0.13)$ & $0.02(0.01)$ & $0.24(0.40)$ \\
$\lambda_{c_{y}, e}$ & $0.12(0.02)$ & $0.09(0.01)$ & $0.59(0.09)$ & $0.54(0.01)$ \\
$\lambda_{c_{y}, h}$ & $0.10(0.03)$ & $0.12(0.04)$ & $0.31(0.01)$ & $0.29(0.06)$ \\
$\lambda_{c_{e}, h}$ & $0.37(0.03)$ & $0.46(0.05)$ & $-0.20(0.05)$ & $-0.40(0.10)$ \\
$\mu_{y}$ & $0.89(0.13)$ & $0.88(0.13)$ & $0.66(0.10)$ & $0.77(0.09)$ \\
$\mu_{e}$ & $-0.34(0.14)$ & $-0.43(0.17)$ & $-0.44(0.12)$ & $-0.56(0.12)$ \\
\hline
\end{tabular}

movements, but there is no evidence that the structural relationship between the variables changed. This is in line with the results obtained by Stock and Watson (2012), who find that the Great Recession was driven by the same dynamics as the previous two recessions, and the same relationships between macroeconomic variables held, but the shocks were larger and their composition was different. Similarly, the results do not change drastically when I exclude the 1950s from the sample. The estimated volatilities for the 1960q1-1983q4 sample are lower, but the persistence and the impact coefficients are very similar to the estimates obtained using the longer subsamples.

\section{CONCLUSIONS}

In this paper, I have investigated the importance of a structural change in the relationship between permanent and transitory movements in real macroeconomic activity for explaining the past three jobless recoveries. There is no significant evidence of overhang, neither at the beginning nor at the end of the past three recessions. ${ }^{20}$ There is also no significant evidence that the persistence of the business cycle has changed. These results are consistent with models that emphasize structural changes in the labor market, such as Barnichon's (2010) model that focuses on market rigidities, with Gali and Van Rens' (2010) model that focuses on declining frictions in the labor market, and with the just-in-time hypothesis, which focuses on a switch toward the intensive margin. A large part of the movement 
in employment and hours can still be explained by cyclical fluctuations, and the relative importance of transitory movements has not changed significantly after 1984. A significant part of the dynamics of employment is driven by an increase in the relative importance of demand shocks, and by a change in the sensitivity of employment and hours per employee to these shocks. The change in the responses of the employment and hours per employee cycle explains a large part of the deviation of employment from trend in all three recessions. ${ }^{21}$

\section{NOTES}

1. The two NBER recessions in the early 1980s were treated as a single recession. Treating them as separate recessions does not affect the results significantly. The graph provided here is similar to graphs in other studies and is intended to illustrate the basic differences in the behavior of employment. As pointed out by Koenders and Rogerson (2005), peak-to-trough indexing is not a formal trend-cycle decomposition. However, it can be a useful tool to illustrate the changes in the labor market and to motivate more detailed analysis. The formal trend-cycle decomposition is explained in Sections 3 and 4.

2. Although the overhang concept is particularly emphasized by Berger, the model in his paper also allows structural changes in the labor market to affect the dynamics of employment.

3. In addition, recoveries that are only driven by productivity changes, compositional changes in labor supply, declining labor market participation, outsourcing, increasing leverage ratios due to changes in the housing market, and particularly adverse demand shocks not accompanied by other changes are also frequently mentioned as possible explanations for the last three slow recoveries in employment.

4. The UC trend-cycle decomposition, which allows correlation between the trend and the cycle, directly accounts for the possibility that there are slow adjustments in aggregate employment to permanent shocks. For a detailed explanation of the general case, see Morley et al. (2003) or Sinclair (2009). A brief mathematical explanation for the case considered here is provided in Appendix A.

5. This specification is motivated by the theoretical reallocation model, where shocks other than productivity shocks can affect the employment cycle. The shocks $\eta_{e, t}$ are defined very similarly to the reallocative shocks in Faberman (2008) and Garin et al. (2013). To ensure identification, I assume that the labor trend shocks are not correlated with shocks to the output trend. This assumption is in line with the empirical results obtained by Kahn and Rich (2007) and Francis and Ramey (2009), who show that low-frequency movements in hours and employment can be explained by two separate factors: productivity and demand shocks, and shocks that are not correlated with productivity shocks. Alternatively, the shock $\eta_{e, t}$ could also be interpreted as a slow preference shift as in Rios-Rull and Santaeulalia-Llopis (2010).

6. The hours per employee series is modeled as a stationary series without a stochastic trend. Standard stationarity and unit root tests confirm that the series for hours per employee used here (aggregate hours worked divided by the number of payroll employees) is indeed stationary. The data for $h$ were recentered, making the mean zero.

7. Morley and Singh (2016) introduce impact coefficients into a UC model in their study, which explores the source of the decline in volatility in output after 1984. Similarly, Klinger and Weber (2015) use a UC framework to study the decoupling between output and employment in Germany.

8. Allowing more autoregressive lags does not change the baseline results significantly (neither qualitatively nor quantitatively). Results are available from the author upon request.

9. The Great Moderation (the structural break in the volatility of most real macroeconomic variables) has been well documented in the literature [see, for example, Kim and Nelson (1999) or McConnell and Perez-Quiros (2000)], and there is a general consensus that the break in variance 
occurred between 1983 and 1985. Most of the empirical papers that focus on jobless recoveries also take 1984 as an exogenous break for the dynamics in employment. See, inter alia, Berger (2012). An exception is the paper by Engemann and Owyang (2010), who estimate a univariate smooth transition model for employment, both aggregate and sectoral, where they allow the break date in the speed of adjustment of employment and the dynamics of employment to be endogenous. Their estimated break dates for aggregate employment and employment in most sectors coincide with the start of the Great Moderation, implying that treating the break as exogenous and occurring around 1984 is a plausible assumption.

10. In this paper, I focus on one aspect of the restructuring theory. Namely, I explore whether there is any evidence of overhang at the end of the expansions that would trigger restructuring (i.e., whether employment was above its long-run trend because firms grew "fat").

11. The first subsample is selected to cover the period studied by the theoretical studies for the models tested here. For example, Bachmann's (2012) and Berger's (2012) samples start in the late 1940s. It is, however, important to note that the first subsample includes eight recessions, and the second only three. Several empirical studies, most notably Engemann and Owyang (2010), start their samples in 1960. The results presented here are robust when a shorter subsample is used that starts in 1960 and are discussed in much more detail in Section 5.

12. For example, Sinclair (2009) uses a bivariate model for unemployment and output and finds correlations that are very close to -1 , and Basistha (2009) uses a four-variate model for productivity, inflation, output per capita, and hours per capita and finds that some of the trend variances in the labor market variables are close to 0 .

13. The implied volatilities are calculated using $\operatorname{Trend}_{e, t}=\gamma \tau_{y, t}+\tau_{e, t}$, and $c_{e, t}=e_{t}-\operatorname{Trend}_{e, t}$.

14. The correlation between the total trend and the cycle provides a measure of the speed of adjustment of the cyclical component of employment to permanent movements. See, for example, Sinclair (2009). A brief explanation is also provided in Appendix A.

15. If there were overhang, employment would be above its long-run trend, and the cyclical part of employment would be positive.

16. The cumulative decrease is calculated as the cumulative change in log employment due to the particular shock in the four quarters following the trough (the area below the graph in the four quarters following the trough). Twelve months is selected as a reasonable benchmark, because the longest timespan for employment to return to its prerecession level (a net change of zero) before 1984 was twelve months.

17. If the change in persistence is taken out of the theoretical model and the focus is only on shocks that happen to be smaller for exogenous reasons, the persistence/amplitude theory is akin to the wellknown "good/bad luck" hypothesis in the literature that links monetary policy conduct and the Great Moderation [see, for example, Kim et al. (2008) for discussion of the "good luck hypothesis"].

18. For the sake of completeness, I also repeat the same experiment, changing only one set of the autoregressive parameters. The results from the counterfactual analysis are available upon request.

19. Even though the AR coefficients did not change significantly, and the cyclical component still plays a very important role, if one were to look only at the growth rates of employment, the results presented here would lead to a "loss of cyclicality" in the employment growth series, which is in line with the findings of Engemann and Owyang (2010).

20. It is important to note that the results obtained here are also consistent with Berger's (2012) hypothesis that there was a change in labor market frictions, but they are not consistent with his hypothesis that firms grew "fat" by the end of the expansions.

21. The results from the UC model indicate that retraining programs could mitigate some of the drop in employment that is caused by permanent shocks, but because a large part of the joblessness is cyclical in nature, there is also room for monetary and fiscal policy. The results presented here are also consistent with the findings of Francis et al. (2013), who use state-level data to study the impact of policy on the speed of the recoveries at the state level. They find no significant impact of fiscal policy, but a significant impact on the speed of the recovery when monetary policy is used to stimulate the economy. 


\section{REFERENCES}

Andolfatto, D. and G. Macdonald (2005) Jobless Recoveries. Washington University in St. Louis working paper.

Bachmann, R. (2012) Understanding the Jobless Recoveries after 1991 and 2001. University of Notre Dame working paper.

Barnichon, R. (2010) Productivity and unemployment over the business cycle. Journal of Monetary Economics 57, 1013-1025.

Basistha, A. (2009) Hours per capita and productivity: Evidence from correlated unobserved components model. Journal of Applied Econometrics 24, 187-206.

Berger, D. (2012) Countercyclical Restructuring and Jobless Recoveries. Yale University working paper.

Burger, J. and J. Schwartz (2015) Productive recessions and jobless recoveries. Contemporary Economic Policy 3(4), 636-648.

Engemann, K.M. and M.T. Owyang (2010) Whatever happened to the business cycle? A Bayesian analysis of jobless recoveries. Macroeconomic Dynamics 14, 709-726.

Faberman, R.J. (2008) Job Flows, Jobless Recoveries, and the Great Moderation. Philadelphia Federal Reserve Bank working paper.

Francis, N., L. Jackson, and M. Owyang (2013) Countercyclical Policy and the Speed of Recovery after Recessions. Federal Reserve Bank of St. Louis working paper.

Francis, N. and V. Ramey (2009) A century of work and leisure. American Economic Journal: Macroeconomics 1(2), 189-224.

Gali, J. (1999) Technology, employment, and the business cycle: Do technology shocks explain aggregate fluctuations? American Economic Review 89, 249-271.

Gali, J. and P. Rabanal (2004) Technology shocks and aggregate fluctuations: How well does the real business cycle model fit postwar U.S. data? NBER Macroeconomics Annual 19, 225-228.

Gali, J., F. Smets, and R. Wouters (2012) Slow Recoveries: A Structural Interpretation. NBER Working Paper 18085.

Gali, J. and T. van Rens (2010) The Vanishing Procyclicality of Labor Productivity. Working paper.

Garin, J.M. Pries and E. Sims (2013) Reallocation and the Changing Nature of Economic Fluctuations. University of Notre Dame working paper.

Gomme, P. (2005) Accounting for the Jobless Recoveries. Federal Reserve Bank of Cleveland working paper.

Groshen, E.L. and S. Potter (2003) Has structural change contributed to a jobless recovery? Current Issues in Economics and Finance 9, 1-7.

Hodgson, A., S.L. Schreft, and A. Singh (2005) Jobless recoveries and the wait-and-see hypothesis. Federal Reserve Bank of Kansas City Economic Review 90, 81-99.

Jaimovich, N. and H.E. Siu (2012) The Trend Is the Cycle: Job Polarization and Jobless Recoveries. Duke University working paper.

Kahn, J. and R. Rich (2007) Tracking the new economy: Using growth theory to detect changes in trend productivity. Journal of Monetary Economics 54, 1670-1701.

Kim, C.J., J. Morley, and J. Piger (2008) Bayesian counterfactual analysis of the sources of the Great Moderation. Journal of Applied Econometrics 23, 615-638.

Kim, C.J. and C. Nelson (1999) Has the U.S. economy become more stable? A Bayesian approach based on a Markov-switching model of the business cycle. Review Of Economics and Statistics 81, 608-616.

Klinger, S. and E. Weber (2015) On GDP-Employment Decoupling in Germany: A Contribution to Explaining the Productivity Puzzle. Institute for Employment Research (IAB) working paper.

Koenders, K. and R. Rogerson (2005) Organizational dynamics and the business cycle: A view on jobless recoveries. Federal Reserve Bank of St. Louis Review 87(4), 555-579.

McConnell, M.M. and G. Perez-Quiros. (2000) Output fluctuations in the United States: What has changed since the early 1980's? American Economic Review 90, 1464-1676.

Morley, J., C. Nelson, and E. Zivot (2003) Why are Beveridge-Nelson and unobserved-component decompositions of GDP so different? Review of Economics and Statistics 85, 235-243. 
Morley, J. and A. Singh (in press) Inventory shocks and the Great Moderation. Journal of Money, Credit and Banking.

Ramey, V.A. and D.J. Vine (2006) Declining volatility in the U.S. automobile industry. American Economic Review 96, 1876-1889.

Rios-Rull, J.V. and R. Santaeulalia-Llopis (2010) Redistributive shocks and productivity shocks. Journal of Monetary Economics 57, 931-948.

Santaeulalia-Llopis, R. (2012) How Much are SVARs with Long-Run Restrictions Missing without Cyclically Moving Factor Shares? Washington University in St. Louis working paper.

Schreft, S.L. and A. Singh (2003) A closer look at Jobless recoveries. Federal Reserve Bank of Kansas City Economic Review 88, 45-73.

Sinclair, T. (2009) The relationships between permanent and transitory movements in U.S. output and the unemployment rate. Journal of Money, Credit and Banking 88, 529-542 .

Sinclair, T. (2010) Asymmetry in the business cycle: Friedman's plucking model with correlated innovations. Studies in Nonlinear Dynamics and Econometrics 14(1), Article 3.

Stock, J. and M. Watson (2012) Disentangling the Channels of the 2007-2009 Recession. Princeton University working paper.

\section{APPENDIX A: STATE-SPACE REPRESENTATION FOR THE UNOBSERVED-COMPONENTS MODEL AND DISCUSSION OF THE IMPACT PARAMETERS}

The measurement equation for the model given by equations (1)-(9) is

$$
\left[\begin{array}{l}
y_{t} \\
e_{t} \\
h_{t}
\end{array}\right]=\left[\begin{array}{llllllll}
1 & 0 & 1 & 0 & 0 & 0 & 0 & 0 \\
\gamma & 0 & 0 & 0 & 1 & 0 & 0 & 0 \\
0 & 0 & 0 & 0 & 0 & 0 & 1 & 0
\end{array}\right] \cdot \beta_{t},
$$

where $\beta_{t}=\left[\begin{array}{llllll}\tau_{y t} & \tau_{e t} & c_{y t} & c_{y t-1} & c_{e t} & c_{e t-1} \\ c_{h t} & c_{h t-1}\end{array}\right]$ and the transition equation is

$$
\beta_{t}=\mu_{t}+F \beta_{t-1}+u_{t},
$$

where $\mu=\left[\begin{array}{llllllll}\mu_{1} & \mu_{2} & 0 & 0 & 0 & 0 & \mu_{3} & 0\end{array}\right]^{\prime}$ and $u_{t}=\left[\begin{array}{llllllll}\eta_{y t} & \eta_{e t} & u_{y t} & 0 & u_{e t} & 0 & u_{h t} & 0\end{array}\right]^{\prime}$, where $u_{x t}$ is the linear combination of structural shocks corresponding to the right-hand side of the equation that defines the behavior of the cyclical component of each variable, given by equations (7)-(9). The transition matrix $F$ is given by

$$
F=\left[\begin{array}{cccccccc}
1 & 0 & 0 & 0 & 0 & 0 & 0 & 0 \\
0 & 1 & 0 & 0 & 0 & 0 & 0 & 0 \\
0 & 0 & \phi_{y 1} & \phi_{y 2} & 0 & 0 & 0 & 0 \\
0 & 0 & 1 & 0 & 0 & 0 & 0 & 0 \\
0 & 0 & 0 & 0 & \phi_{e 1} & \phi_{e 2} & 0 & 0 \\
0 & 0 & 0 & 0 & 1 & 0 & 0 & 0 \\
0 & 0 & 0 & 0 & 0 & 0 & \phi_{h 1} & \phi_{h 2} \\
0 & 0 & 0 & 0 & 0 & 0 & 1 & 0
\end{array}\right] .
$$

The state-space representation is identical for each subsample. The variance-covariance matrix $Q$ is equal to $E\left[u_{t} u_{t}^{\prime}\right]$. For simplicity, the hours per employee series is centered on zero, which reduces the dimension of the parameter space by setting $\mu_{h}=0$. 
The model and the estimation procedure do not impose the coefficients $\lambda_{i j}$ being different from zero, but it is important to allow them to be potentially different from zero. By allowing $\lambda_{\tau_{y}, e}$ and $\lambda_{\tau_{e}, e}$ to be different from zero and allowing feedback from the trend to the cycle, the model directly accounts for the possibility that permanent shocks that will increase output and employment in the short run might have a negative impact on the cyclical component of employment and cause temporary declines in employment. The general logic is as follows: Let $\eta$ be positive, but $\lambda_{\tau_{y}, e}$ negative (for illustration, consider a case close to the empirically relevant case, where the estimated $\lambda_{\tau_{y}, e}<0$ and is fairly large in absolute value). Then the total change on impact in employment due to this shock $\eta_{t}$ will be

$$
\Delta e_{t}=\Delta \operatorname{Trend}_{\mathrm{emp}}+\Delta \text { cycle }_{\mathrm{emp}}=\gamma \eta_{t}+\lambda_{\tau_{y}, e} \eta_{t}=\left(\gamma+\lambda_{\tau_{y}, e}\right) \eta_{t} .
$$

The long-run level of employment shifts up by $\gamma \eta_{t}$. However, the impact response is smaller than $\gamma \eta_{t}$, because the cycle declines on impact by $\lambda_{\tau_{y}, e} \eta_{t}$. This is essentially a negative shock $\lambda_{\tau_{y, e}} \eta_{t}$ to the cycle that will propagate for several periods because of the autoregressive part of the cycle, but that will eventually die out because the cycle is stationary. Once the effects on the cycle become negligible, the long-run increase $\gamma \eta_{t}$ will dominate the temporary decrease. For illustration, one can think of this shock as, say, a restructuring shock that gets the economy out of a recession that will eventually lead to higher productivity and higher trend output and employment, but that causes a temporary decline in employment because of longer times needed to train employees, as suggested by, for example, Groshen and Potter (2003).

\section{APPENDIX B: BAYESIAN ESTIMATION}

The results presented in the text are obtained using a multiblock Metropolis-Hastings algorithm with a tailored proposal distribution. For convenience, the prior for $\lambda_{\eta_{y}, y}$ was a truncated normal distributions on $(-\infty, 0)$ with mean -0.5 and variance equal to 1 . This prior is based on the MLE estimates and on results of previous studies [for example, Morley et al. (2003), Basistha (2009), Sinclair (2009), or Morley and Singh (2016)]. This restriction is also consistent with impulse responses from studies that use VECM models. It is important to note that the truncated prior is merely a convenient tool to ensure slightly faster convergence. The results were robust to the choice of priors, and using more diffuse priors or different families of priors does not affect the results significantly.

The priors for the initial values for the stochastic trends were Gaussian distributions that were centered at the initial observations and had variance equal to 10 (see Table B.1). The $\mathrm{MH}$ algorithm was implemented as follows:

1. Start with arbitrary values for the parameter coefficients.

2. Conditional on the parameter coefficients, obtain the smoothed estimates for the state variables.

3. At the $i$ th iteration, conditional on the parameter vector $\theta^{(i)}$ and the state variables, draw a new value for the $J$-dimensional parameter block $\theta_{b}$ from a Student $t$ proposal with mean $\theta_{b}^{(i)}$, scale equal to the $J$-by- $J$ subblock of the inverse of the Hessian matrix evaluated at $\theta^{(i)}$, and 15 degrees of freedom. If the value is accepted, update $\theta^{i}$ to reflect the update when calculating the Hessian for the other blocks.

4. Repeat step 2 until all parameters are updated, and update $\theta^{i+1}$. 
TABLE B.1. Priors for the Bayesian estimation

\begin{tabular}{llcc}
\hline & \multicolumn{1}{c}{ Family } & Mean & Variance \\
\hline$\left(\phi_{i 1} \phi_{i 2}\right)$ & Truncated normal, to ensure stationarity & $(00)$ & $I_{2}$ \\
$\sigma_{\text {structural shock }}^{2}$ & Inverse gamma & 1 & 5 \\
$\lambda_{\eta_{y}, y}$ & Truncated normal & -0.5 & 1 \\
$\lambda_{i,, j_{i \neq \eta_{y} y}}$ & Normal & 0 & 10 \\
$\mu_{i}$ & Normal & 0 & 10 \\
\hline
\end{tabular}

Note: $i=y, e$ The data for $h$ were recentered, making the mean zero.

The results presented in the text were obtained using 80,000 iterations of the MH chain, after a burn-in of 20,000 draws. To ensure convergence, the chain was started from several different values. To obtain the trend and cycle estimates, I use the Kalman filter and the related prediction-error decomposition. 